IFN Working Paper No. 920, 2012

\title{
Social Trust and Central-Bank Independence
}

\author{
Niclas Berggren, Sven-Olov Daunfeldt and \\ Jörgen Hellström
}




\title{
Social trust and central-bank independence
}

\author{
By Niclas Berggren*, Sven-Olov Daunfeldt ${ }^{\dagger}$, and Jörgen Hellström ${ }^{\ddagger}$ \\ * Research Institute of Industrial Economics (IFN), and Department of Institutional Economics, University of \\ Economics in Prague \\ ${ }^{\dagger}$ HUI Research AB, SE-103 29 Stockholm, Sweden, and Department of Economics, Dalarna University; e-mail: \\ sven-olov.daunfeldt@hui.se \\ ‡Umeå School of Business and Economics, Umeå University
}

\begin{abstract}
Central banks have been made more independent in many countries. A common rationale has been the existence of a credibility (or lack-of-trust) problem for monetary policy. This indicates a possible and until now unexplored link between social trust and central-bank independence. Our empirical findings, based on data from 149 countries, confirm that there is such a link, in the form of a u-shaped relationship. We suggest that two factors help explain this finding: the need for this kind of reform and the ability with which it can be implemented. At low trust levels, the need for central-bank independence is strong enough to dominate the low ability; at high trust levels the ability for reform is high and dominates the low need; at intermediate trust levels there is neither need nor ability strong enough to generate very independent central banks.
\end{abstract}

JEL classifications: E52, E58, P48, Z13. 


\section{Introduction}

Social trust - as measured by the share of people who think that most people can be trusted - seems conducive to the reaching of quite a few social and economic goals. For example, it is positively related to economic growth (Zak and Knack, 2001; Berggren et al., 2008), trade (Guiso et al., 2009), stock-market size (Guiso et al., 2008), the welfare state (Bergh and Bjørnskov Bjørnskov, 2011), financial integration (Ekinci et al., 2007), subjective well-being (Helliwell and Wang, 2010), and health (Rose, 2000). Societies in which people think that most people can be trusted thus tend to exhibit many widely valued qualities that are lacking in low-trust societies.

We propose to study whether trust affects central-bank independence. Pinpointing the determinants of this kind of independence is of interest, since previous studies have generally found it to entail low inflation rates - see, e.g., Berger et al. (2001), Acemoglu et al. (2008), Crowe and Meade (2008) and Cukierman (2008) - which is a generally embraced policy goal. Our hypothesis is that social trust is a factor of importance - in fact, there is a connection between the rationale for making central banks more independent and trust, in that the quest to give central banks an independent role largely builds on a perceived credibility (or lack-of-trust) problem. According to the literature on time-inconsistency in monetary policy, starting with Kydland and Prescott (1977) and Barro and Gordon (1983), policymakers have an incentive to renege on their pronounced inflation goals through surprise inflation, which causes the public to eventually not trust announcements of such goals. The equilibrium outcome is the inflation rate at which no further gains can be obtained through inflation surprises. This situation entails inefficiently high inflation with no reduction in unemployment. Rogoff's (1985) solution involves the delegation of monetary policymaking to a conservative central banker, that is, one that puts a lower weight on the loss associated with unemployment than policymakers, resulting in lower inflation in equilibrium. Despite this connection, no previous study has to our knowledge analyzed the relationship between social trust and central-bank independence.

We study social and not particularized trust. ${ }^{1}$ The former is unrelated to information about specific persons or organizations - it captures a basic outlook on people in general - while the latter refers to trust in people or organizations one knows or knows something about. Our primary motivation for looking at social trust is that we theorize that central-bank independence is a function of trust towards 'everybody', since a decision to delegate power arguably depends on an assessment, by those undertaking the delegating, of the reactions of very broad groups of unidentified actors,

\footnotetext{
${ }^{1}$ On conceptual issues in the trust literature, see Bjørnskov (2007) and Naef and Schupp (2009).
} 
such as politicians, voters and civil servants. Only social trust, we argue, fully captures this broad, trusting outlook that is related to a willingness to undertake reform. ${ }^{2}$

To understand the relationship between trust and central-bank independence we propose two mechanisms that work in opposite directions. On the one hand, there is the ability with which reforms that establish this type of independence can be undertaken. This ability is positively related to trust: the more people trust others, the easier it is to agree on delegation of power and to overcome social conflict and strife. For example, it cannot only be expected to be the case, in a setting with high social trust, that politicians trust each other but also that they trust independent central bankers. On the other hand, there is the need for reform. In a setting with low trust, the credibility problem of monetary policy is plausibly very high, and the need to follow Rogoff (1985) and implement central-bank independence reforms is therefore seen as more urgent. At high trust levels, this need is much smaller, since trust can be seen as an informal institution that serves as a substitute for a credible formal institution. In all, the two factors identified indicate a negative relationship between trust and central-bank independence. If the need is sufficiently strong at low trust levels, and if the ability is sufficiently high at high trust levels, we obtain a u-shaped relationship when putting the two mechanisms together.

We investigate the relationship empirically by making use of Arnone's et al. (2007) centralbank independence index, in order to measure our dependent variable. Social trust is defined as the share of the population that answers 'yes' to the first part of the question 'In general, do you think most people can be trusted or can't you be too careful?', as measured by the average of all available and credible observations in the five waves of the World Values Survey and some complementary sources. Previous studies of the determinants of central-bank independence - e.g., de Haan and van't Hag (1995), Hayo and Hefeker (2002) and Carmignani et al. (2008) - do not include social trust.

This study most closely relates to Hayo and Voigt (2008), who look at the effects of de facto judicial independence and trust in the legal system on central bank independence and inflation rates. They find that both factors are positively related to independence and negatively related to inflation rates. The idea is that there is a second-order commitment problem (Moser, 1999), such that politicians may have an incentive to influence monetary policy by trying to intervene in the work of the independent central bank, and that an independent and trusted legal system may make such attempts difficult to undertake. Note that the trust measure, and the suggested mechanism for why this kind of trust matters, is different compared to the one used in this study, social trust. We also

\footnotetext{
${ }^{2}$ Studying the effects on central-bank independence of trust in the central bank could be a topic for future research, but it would capture a much more narrow aspect of trust, looking only at the public's attitudes toward one particular institution.
} 
use another outcome variable: instead of looking at turnover rates of central-bank governors, which arguably is an imprecise measure of central-bank independence, ${ }^{3}$ we use a central-bank independence index described in more detail in Section 3.

Our results indeed suggest a u-shaped relationship between social trust and the level of central bank independence. In general, low- and high-trusting societies both tend to delegate considerable power from politicians to independent central bankers, while countries with intermediate levels have a lower degree of central-bank independence. Thus, the institutional framework in this area seems to be affected by the level of social trust, a relationship that has not been recognized previously.

The rest of the paper is structured as follows. We begin, in Section 2, with a theoretical discussion of the relationship between social trust and central-bank independence. We then present the data (Section 3), the empirical strategy (Section 4) and the results (Section 5). Concluding remarks close the paper (Section 6).

\section{Theoretical preliminaries}

We argue that the relationship between social trust and central-bank independence is a function of two factors: the ability to establish independence and the perceived need to do so. We discuss these two factors in turn and conclude the section by putting them together.

\subsection{The ability to undertake central-bank independence reform}

In order for mutually beneficial agreements to come about, actors need assurance that they will not be exploited by opportunists and that agreements are reliable. In simple and standardized transactions, this is not a big problem, but as soon as more people are involved, when the social distance between them is large, when consequences are uncertain, when monitoring is difficult, when there is a temporal feature to the agreement and when the object of the transaction is complex, some method of assurance increases the probability of agreement. As explained by Knack

\footnotetext{
${ }^{3}$ The underlying assumption is that the central bank is not independent if central bank governors are frequently replaced. However, the turnover rate for a central-bank governor can be low because the governor is acting on direct orders from the government. One could argue that truly dependent central banks will be characterized by very low turnover rates, as the government does not have any reason to replace their governors. Furthermore, it could also be that governors are often replaced for other reasons than being at odds with the government, such as being offered new jobs elsewhere.
} 
and Keefer (1997), this can come about through written contracts, aided by formal legal institutions, but they note that this is a costly and imperfect method. An alternative mechanism, which reduces the need for contracts and formal institutions for agreements to come about, is provided by trust.

This reasoning can also be applied to political decision-making. When reforms are contemplated, there are many obstacles to overcome. Politicians may need assurance that other politicians will not undermine their decisions later on; that bureaucrats will co-operate and not shirk or work for a different agenda; that voters will not quickly withdraw their support as a result of the reforms; and that interest groups will not spend large resources to block or undo the reforms. Such assurance can to some extent come from credible formal institutions, such as a division of power with a strong and independent legal system acting as a check on legislation (Hayo and Voigt, 2008). But as in the case of economic transactions, formal institutions are costly and imperfect, and trust can provide an alternative mechanism through which politicians can obtain assurance of the kinds just mentioned, making them more inclined to and able to undertake reforms.

More specifically, if politicians trust each other, both within and between party groups, agreement on reform will be easier (Boix and Posner, 1998; Knack, 2002). Interests are more easily aligned, and gridlock less probable, when political actors do not perceive other such actors to be opportunistic and when they believe that agreements will be adhered to. Two cases illustrate this point. Den Butter and Mosch (2003) find that trust among policymakers and among other key actors on the political scene in the Netherlands greatly facilitated the implementation of reforms that contributed to a strong economic development. Bergh and Erlingsson (2009) likewise find that a key explanation for important policy reforms in Sweden, such as a major pension reform and economic liberalization, was the result of a pragmatic consensus orientation that is arguably rooted in the high level of social trust in this country.

Second, if politicians trust bureaucrats, this means that they are more prone to delegate power. A major reason for this is that trust mitigates the principal-agent problem; another is that it fosters a sense of co-operation (Boix and Posner, 1998). Bjørnskov (2010) shows empirically that public officials are more honest and therefore more trustworthy in societies with high trust.

Third, if politicians trust voters, the latter are believed to assess politicians in a generous and long-term manner, which may facilitate reforms that are socially beneficial in the longer run albeit costly during a transition. Trust in this direction may stem from an expectation of trust in the other direction: social trust implies trust 'overall'. For example, if compensation is promised to cover temporary losses, trust from voters to politicians increases the perceived credibility of such a promise, which should reduce resistance to reforms (Heinemann and Tanz, 2008). Reformers are 
then less worried about immediate electoral punishment. ${ }^{4}$ Furthermore, if voters are trustworthy in this way, this also implies that interest-group activity can be expected to be lower. Instead of forming polarizing groups, people are to a larger degree characterized by community-oriented and cooperative sentiments and by taking the interests of people in general into account (Boix and Posner, 1998). ${ }^{5}$ As a result, the costs of securing agreement can be expected to be lower and the sustainability of reforms to be higher. This in turn increases the propensity to undertake reforms.

This reasoning can be applied to level of central-bank independence and the reforms that precede and determine it. Initially, there are some politicians who consider a reform desirable, perhaps because they think it will help bring about lower inflation. The logic of this idea is that due to the time-inconsistency problem identified by Kydland and Prescott (1977) it can be beneficial to insulate monetary policy-making from the incentives of politicians by delegating that authority to a central bank with a specified goal (Rogoff, 1985). As Neumann (1991) and Hayo and Voigt (2008) clarify, for such a reform to be credible, independence needs to be built on a certain institutional structure that guarantees the absence of meddling from the politicians. However, McCallum (1997) and Hayo and Voigt (2008) also point out that there is a second-order commitment problem, such that politicians may still have an incentive to intervene in the formally but not necessarily actually independent central bank, e.g., by changing its goals or constitutional status and by replacing governors or affecting their working conditions. While they find that de facto judicial independence coupled with the public's trust in legal institutions seem to solve large parts of this problem, we propose that social trust offers an alternative solution to the problem. If trust is present, credibility can be established more easily in a given institutional setting.

Hence, we suggest that trust is positively related to the chance for and size of reform: by making enduring agreement between politicians easier, by politicians having confidence in independent central bankers, by politicians believing that voters will regard the reform generously, and by politicians not seeing a risk for interest-group activity aiming to undermine reform attempts.

Lastly, although we discuss trust between various groups, we indeed see this section as exploring the consequences of social trust, which encompasses people in general. This means that it encompasses groups of people, like politicians, bureaucrats as voters, among others, as well - but not because they are assessed on the basis of how they have acted in their capacities as politicians,

\footnotetext{
${ }^{4}$ One aspect of this is that the democratic accountability problem of independent central banks (Eijffinger and Hoeberichts, 2002 ) is plausibly (perceived as) less severe in high-trusting socities, making reforms more probable and wide-ranging.

${ }^{5}$ Hall and Thelen (2009) stress that institutional reform originates in political compromise that has to overcome distributional conflict. Compromise and taking a social perspective is more probable in the presence of trust.
} 
bureaucrats and voters but because they are part of a society in which an attitude of general trust is present. As Knack and Keefer (1997, p.1253) put it: 'Government officials in societies with higher [social] trust may be perceived as more trustworthy, and their policy pronouncements as thus being more credible.' Furthermore, social trust applies to 'all' groups without any particular differentiation, including the three identified in this section, unlike particularized trust, e.g., in the form of 'institutional' trust, which is directed narrowly at identified groups on the basis of knowledge about have they have carried out specific tasks. The difference between the two with regard to different groups is not, then, that the one does not relate to groups while the other one does but that social trust covers groups as part of people in general while particularized trust covers groups qua groups evaluated on group-specific grounds. Yet another aspect of the reasoning of this section that makes it compatible with social trust being at work is that these trusting relationships as a rule extend over time and concern not only today's members of these groups but also tomorrow's. Politicians contemplating reform can be expected to be more prone to do so if they believe in the good intentions and promise-keeping qualities of people in general, which include future political decisionmakers. Particularized trust, on the other hand, is essentially backward-looking.

We believe that we have established a good argument for why the ability to undertake centralbank independence reform is increasing in social trust. This does not imply that there is no such ability at low trust levels, only that it is lower.

\subsection{The need to undertake central-bank independence reform}

A second factor of importance is the perceived need to make the central bank more independent. This perceived need follows from the credibility problem of monetary policy, which is big at low levels of trust and which is decreasing in trust. The reason is that trust can be expected to reduce the problem of time-inconsistency: if there is mutual trust between politicians and voters, the latter do not expect the former to renege on their stated commitments, and the former - in striving to continue to be perceived as trustworthy - will hesitate to increase inflation surprisingly. If politicians do not trust each other, there is easily a suspicion that opposing parties will default on their promises in this area in the future. With low trust there is hence weak 'social discipline' on monetary policy that makes central-bank independence essential for achieving credibility for a low-inflation approach. The absence of such discipline also implies a low propensity for punishment of opportunism, which Bjørnskov (2010) argues is present in high-trust settings. When people trust each other, they have high expectations and will react more strongly if the agents misbehave, which 
functions as an incentive not to misbehave. This in turn makes the perceived need for institutional reform smaller: monetary policy-makers are assumed to behave well and avoid such things as inflation surprises.

\subsection{Putting ability and need together}

When putting ability and perceived need together, we can illustrate the relationship between trust and central-bank independence as in Fig. 1.

\section{[Fig. 1 near here]}

We have the two curves $\mathrm{A}$ and $\mathrm{N}$. The former refers to the ability of relevant decision-makers to implement reform in this area (as explicated in Section 2.1); the latter refers to the perceived need to have reform (as explicated in Section 2.2). Summing the two curves produces the u-shaped curve $\mathrm{A}+\mathrm{N}$, which gives the full, or net, relationship between our two main variables. We now proceed to the empirical analysis to see whether the data are able to confirm this theoretical conceptualization of the relationship.

\section{Data}

\subsection{Dependent variable}

To measure central-bank independence, our dependent variable, we make use of the index of Arnone et al. (2007). They apply the methodology of Grilli et al. (1991) to calculate a new index measuring central-bank independence for 163 central banks in 2003. This index measures two things: the ability of central banks to choose the final goal of monetary policy and how independently central banks can choose monetary-policy instruments.

The independence of the central bank to choose the final goal of monetary policy is based on eight criteria, taking the value one (and zero otherwise) in each case if: (i) the central bank governor is appointed without government involvement; (ii) the central bank governor is appointed for more than 5 years; (iii) all of the members in the central bank governing board are appointed without government involvement; (iv) the board members are appointed for more than five years; (v) there is 
mandatory participation of government representatives on the board; (vi) no government approval is required for formulation of monetary policy; (vi) the central bank is legally obliged to pursue monetary stability as one of its objectives; and (viii) there are legal provisions that strengthen the central bank's position in the event of a conflict with the government.

The independence of the central bank to choose its monetary-policy objectives is based on the following criteria, taking the value one (and zero otherwise) in each case if: (i) the government cannot obtain direct credit from the central bank; (ii) when credits are available they are extended to the government at market interest rates; (iii) credit to the government is temporary; (iv) credit given to government is for a limited amount; $(v)$ the central bank does not participate in the primary market for public debt; (vi) the central bank is responsible for setting the policy rate; and (vii) the central bank has no responsibility for overseeing the banking sector (two points) or shares such responsibility (one point).

All these factors are standardized and summarized and yield our dependent variable, centralbank independence $(C B I)$, which ranges from zero (low independence) to one (high independence).

Merging the data for the $\mathrm{CBI}$ index with country background data renders a sample covering 149 countries for which the level of central-bank independence is observed at the end of 2003 $\left(C B I_{03}\right)$. Table 1 shows descriptive statistics. For comparison, we also include data for the centralbank independence of 73 countries in $1989\left(C B I_{89}\right)$, as reported by Cukierman et al. (1992).

\section{[Table 1 near here]}

Table 1 shows that the level of CBI has increased dramatically around the world, confirming Cukierman's $(2008$, p.723) statement that 'most central banks in today's world enjoy substantially higher levels of both legal and actual independence than twenty years ago or earlier.' This interpretation of policy development is also supported by Daunfeldt et al. (2009), who found that 89 of 132 studied countries had implemented institutional reforms that formally established the independence of central banks during the period 1980-2005. 


\subsection{Explanatory variables}

Our main explanatory variable is social trust, defined as the share of the population that answers 'yes' to the first part of the question: 'In general, do you think most people can be trusted or can't you be too careful?' This question is correlated with measures of honest behavior (Knack and Keefer, 1997; Bjørnskov, 2007); the share of people who do not reply to it is very low, typically below $5 \%$, which indicates that people grasp it clearly (Nannestad, 2008); both in-depth interviews (Uslaner, 2002) and the fact that replies to the question predict outcomes of trust experiments reasonably well when the stakes of anonymized games are of economic significance, suggest that the question measures trust in strangers or people whom the respondents do not know (Sapienza et al., 2007; Ostrom et al., 2009; Thöni et al., 2009). Following Bjørnskov (2007), we use the average of all available and credible observations in the five waves of the World Values Survey, supplemented by data from the LatinoBarómetro, the AfroBarometer, the Asian and East Asia Barometers, and the Danish Social Capital Project. All of these surveys have asked the same trust question. ${ }^{6}$ This variable is quite stable over time, and by making use of averages of several data points we reduce the risk of having atypical data of individual years in our dataset. As the effect of social trust on central-bank independence is hypothesized, in Section 2, to be non-linear, we include a linear as well as a quadratic trust variable in our regressions.

In addition, we use a set of economic and political control variables, based on previous studies that have looked at the determinants of central-bank independence. Economic characteristics included in the empirical analysis are the level of inflation, measured by the annualized percentage change in consumer prices from IMF (2011); unemployment, from ILO (2011); gross domestic product (GDP) per capita in US dollars, and the use of fund and credits from the International Monetary Fund, both from World Bank (2011).

The motivation for including inflation is that countries characterized by high inflation could be more prone to implement central-bank independence reforms than countries with low inflation. On the other hand, low values might be an effect of an historically high level of central-bank independence, suggesting that there might be a reverse-causality problem. As for unemployment, the time-inconsistency model of monetary policy implies that the benefit of surprise inflation is higher the larger the gap between the desired unemployment rate and the natural rate of unemployment. Hence, to the extent that low inflation is valued highly, countries with high unemployment could have a larger incentive to increase the level of central-bank independence

\footnotetext{
${ }^{6}$ We consider the Iranian and Chinese World Values Survey data, as well as the Canadian 2000 trust value in the World Values Survey, as unreliable and exclude them (Uslaner, 2002; Bjørnskov, 2007).
} 
(Cukierman, 1994). GDP per capita is a standard variable to differentiate between countries on the basis of wealth, but it is unclear what the sign of a possible effect is. As for IMF credits, it has been suggested that reforms to increase central-bank independence have been implemented, especially in less-developed countries, to signal creditworthiness to foreign investors (Maxfield, 1997). We therefore expect this measure to be positively related to the level of central-bank independence.

Political factors used in the analysis are political fragmentation in parliament and whether the country is a federation or not (from Lundell and Karvonen, 2003), the number of previous coups (from Marshall and Marshall, 2007), and a dummy capturing whether the country is a democracy or not (from Cheibub et al., 2010). Political fragmentation has a theoretically ambiguous effect: it makes it more difficult to agree on making the central bank more independent, but it also makes the politicians more motivated to tie the hands of the opposition when those in power alternate. The federation dummy takes the value one if the country can be classified as a federation, and zero otherwise. It is a measure of institutional checks and balances, which could be expected to affect the level of central-bank independence, as central banks in such countries tend to be more independent to begin with (Moser, 1999). The number of coups in previous periods is included as a measure of political instability. It is proxied with an exponential weighted moving average (EWMA, 20 years) of the number of coups in the country. The weights for successive past observations in the moving average are calculated as $(1-\lambda) \lambda^{0},(1-\lambda) \lambda^{1},(1-\lambda) \lambda^{2}, \ldots$, where $\lambda$ is $0.75 .^{7}$ We include this since politically unstable countries are plausibly less prone to concern themselves with institutional reforms that delegate power to central banks (Cukierman, 1994). Lastly, the democracy dummy is used since policymakers in democratic countries are arguably more likely to delegate power from themselves to central bankers.

We add two more control variables. The first is the $\mathrm{CBI}$ index developed by Cukierman et al. (1992), to analyze whether the 2003 level of CBI depends on the level of CBI before the intense reform period of central banks took its start in the early 1990s. The second is a dummy for members of the ESCB (European System of Central Banks), since the Maastricht Treaty required the central banks of member states to be independent before the ESCB's establishment date.

\footnotetext{
${ }^{7}$ Many risk management companies (e.g., RiskmetricsTM) use the weight $\lambda=0.94$ in calculations of return volatility measures. In this study three different weights have been tested in the calculation of the EWMA measure to test the sensitivity of the estimation results: $\lambda=0.5, \lambda=0.75$ (the one reported) and $\lambda=0.94$. In general, a lower weight gives more weight to more recent observations. The estimation results for the variable are, however, insensitive to the considered weights, i.e., similar results were obtained for the different weighting schemes.
} 
Finally, we note that missing data is a potential problem for us, as for many other studies using macro data. Since missing data (if not random) can obscure the results, a multiple imputation approach is employed (Graham et al., 2003). ${ }^{8}$ The approach involves three phases. In the first, the missing data are replaced $m$ times to generate $m$ complete data sets. In the second, each of the $m$ complete data sets is analyzed separately. Lastly, the results from the $m$ complete data sets are combined for inference. Multiple imputation has been shown to produce unbiased parameter estimates which reflect the uncertainty associated with the missing observations. The method has further been shown to provide adequate results in presence of high rates of missing data (Schafer and Graham, 2002). An iterative Markov Chain Monte Carlo (MCMC) method (Gilks et al., 1995) is used to impute the missing observations. The MCMC is used to simulate a predictive distribution for the missing observations based on the mean and covariance structure of the observed data. The imputed values are then drawn from this distribution. Rubin (1987) shows that there is little advantage in producing and analyzing more than a few imputed datasets. Based on this, the current study utilizes five imputed sets of data.

The empirical analysis is performed on each of these datasets and the estimation results for each are later combined, using the rules established by Rubin (1987), to produce one set of estimation results. The means, standard deviations and missing observation for all variables (with imputed values) averaged over the five data sets are shown in Table 2.

\section{[Table 2 near here]}

\section{Outline of empirical analysis}

The level of central-bank independence is observed at the end of $2003 .{ }^{9}$ A potential problem when deciding what years of the economic and political background variables to include is that the level of central-bank independence observed in 2003 was achieved through reforms in different years prior to 2003. Analyzing the cross-section of central-bank independence levels in 2003 with explanatory variables measured during the reform period would then risk including values corresponding to time

\footnotetext{
${ }^{8}$ An analysis of missing observation patterns in the current data reveal that observations are not randomly missing.

${ }^{9}$ As indicated in Table 1, the level of central-bank independence is also observed in 1989 for a smaller sample. We do not, however, observe the CBI level over time, which means that we cannot undertake a longitudinal study.
} 
periods after the actual central-bank independence level was achieved. This could bias our inference since, for example, the level of independence would affect inflation.

To avoid this we let the ten-year periods before the years in which central-bank independence reforms occurred (see Daunfeldt et al., 2009) determine the values of the explanatory variables (with the exception of social trust). ${ }^{10}$ Hence, for a country recorded to have undertaken a major centralbank independence reform in 1998, we assume that this was the year when the level of central-bank independence observed in 2003 was achieved. For such a country, we would therefore use the average value of the explanatory variables in 1988-1997, and in this manner we use individual time periods for each country. ${ }^{11}$

Unlike the other explanatory variables, our main variable of interest, social trust, is not measured as the average of annual values during the 1980s or of the ten-year average of the decade before reform was undertaken. Instead, for this variable, we use the average of all available observations, based on all waves from the World Values Survey and complementary surveys asking the same question. This implies that the values derive from a period from the early 1980s until the mid-2000s. We argue that this is not a severe problem, both because social trust is a stable variable that changes little over time and because there is no strong theoretical reason to expect central-bank independence to influence the general level of social trust in a society. In addition, there are relatively few observations available for social trust, which means that we would experience a severe loss in data if we used the same approach as for the other explanatory variables.

Our dependent variable, central-bank independence (CBI), is measured in terms of an index bounded between zero and one. This restriction on the dependent variable makes linear regression unattractive since it may yield fitted values that exceed the lower and upper bound. Also, the effect of explanatory variables tends to be non-linear and the variance tends to decrease when the mean gets closer to one of the boundaries. To account for this feature of the data, we use a regression model based on the beta distribution. Following Ferrari and Cribari-Neto (2004), the density of the beta distribution is parameterized as

$$
f(y \mid \mu, \phi)=\frac{\Gamma(\phi)}{\Gamma(\mu \phi) \Gamma((1-\mu) \phi)} y^{\mu \phi-1}(1-y)^{(1-\mu) \phi-1}, 0<\mathrm{y}<1
$$

\footnotetext{
${ }^{10}$ Models using five-year periods have also been estimated. All results remain qualitatively the same.

${ }^{11}$ As the wave of central-bank independence reforms started in the beginning of 1990s we also, as a robustness test, use the mean values of the explanatory variables from the pre-reform period (1980-1989), using the same time period for all countries. The results are qualitatively similar.
} 
where $E(y)=\mu$ and $\operatorname{var}(y)=V(\mu) /(1+\phi)$ is the mean and variance of the distribution, respectively. Note here that the mean is bounded between zero and one, i.e., $0<\mu<1$, and that $\phi>0$ can be interpreted as a precision parameter in the sense that, for fixed $\mu$, the larger the value of $\phi$, the smaller the variance of $y$. By use of a logit linking function for the mean, explanatory variables are introduced in the model, as follows:

$$
\mu=\frac{\exp ^{x_{i}^{T} \beta}}{1+\exp ^{x_{i}^{T} \beta}},
$$

where $x_{i}^{T}=\left(x_{i 1}, \ldots, x_{i k}\right), i=1, \ldots, n$, are the $k$ explanatory variables for the sample of $n$ countries and $\beta=\left(\beta_{1}, \ldots, \beta_{k}\right)$ is a vector of unknown parameters. The parameters are identified by maximum likelihood based on the above beta density.

\section{Empirical results}

The estimation results, combined over the five imputed data sets and based on the beta distribution, are displayed in Table 3.

\section{[Table 3 near here]}

They indicate a non-linear ( $u$-shaped) relationship between the level of social trust and CBI, quite in line with our theoretical reasoning in Section 2. The hypothesis of a linear relationship against the quadratic alternative is rejected at the $5 \%$ level. This relationship is illustrated in Fig. 2, evaluated at the means of the other explanatory variables and based on the estimates from the beta regression. The results suggest that low-trusting countries have relatively independent central banks, which we interpret as a result of a perceived need for independence in a setting with little confidence in monetary policy-makers. It thus seems that countries with low degrees of trust feel a stronger need to delegate power to independent central banks to achieve credibility for a low-inflation goal. Countries with a high level of social trust likewise have quite independent central banks. Our preferred interpretation is that trust in these countries reflects a high ability to reform, as trust 
facilitates consensus and the reaching of agreement with regard to letting non-politicians making important decisions. Countries at intermediate levels of trust seem to have neither sufficient need nor sufficient ability to establish high independence. The lowest degree of independence is achieved at a trust level of about $37 \%$. The group of countries at or above this level of social trust, which is quite far to the right in the trust distribution, indicating a skewed u-shape, consists mainly of highly developed countries, such as the US, Germany, Japan, Canada, and the Nordic countries.

[Fig. 2 near here]

Highly political fragmented countries have a higher degree of central-bank independence than countries characterized by less political competition, suggesting that politicians may be eager to tie the hands of subsequent governments. The frequency of coups does not seem to influence the level of central-bank independence. However, the democracy dummy is positive and significant, indicating the democratic countries implement more independent central banks than autocracies. The ESCB dummy is positive and statistically significant, capturing that members of the ESCB were required to make their central banks more independent from the politicians.

However, most of the explanatory variables are not statistically significant, which is especially interesting since they are frequently used in the previous literature trying to explain central-bank independence and since social trust has not previously been used for this purpose (de Haan and Van't Hag, 1995; Hayo and Hefeker, 2002; Carmignani et al., 2008; Hayo and Voigt, 2008).

In order to make the size of the effects clear, as well as indicate the loss in efficiency due to missing observations, we also present marginal effects $(\mathrm{ME})$ and the percentage of the total variation due to variation in the point estimates between the five imputed samples in Table 3. The marginal effects show the change in the predicted dependent variable for a $1 \%$ change in the explanatory variable for each variable, while keeping all variables at their mean values. Note here that the marginal effect calculated for social trust varies with the level of social trust due to the non-linear relationship. The relationship (shown in Fig. 2) indicates that a unit increase (of 1 percentage point) in social trust from 3\% (Cape Verde) to 4\% (Trinidad and Tobago) decreases the level of CBI by 0.007 and that a unit increase in social trust from $26 \%$ (e.g., Albania) to $27 \%$ (e.g., Uruguay) decreases the level of $\mathrm{CBI}$ by 0.003 , while a unit increase in social trust from $46 \%$ (e.g., Vietnam) to $47 \%$ (e.g., Australia) increases the level of $C B I$ by 0.002 . The sign switch occurs at $37 \%$. For a shift in social trust from 3\% (Cape Verde) to 37\% (e.g., Austria) the level of CBI falls by 0.126 , while an increase in social 
trust from $37 \%$ (e.g., Austria) to $64 \%$ (Sweden) increases the level of CBI by 0.08 . We consider these effects quite sizable. The uncertainty added due to missing observations for the estimates corresponding to the social trust variables, i.e., the linear and quadratic terms, are $16.6 \%$ and $11.7 \%$, respectively. Despite this added uncertainty due to missing data, the effects are significant at the $5 \%$ level.

\section{Conclusion}

The worldwide increase in central-bank independence is one of the most important and significant trends in economic policy during the two last decades. The theoretical background for this development is the time-inconsistency problem in monetary policy (Kydland and Prescott, 1977; Barro and Gordon, 1983), suggesting that a low inflation goal will not be credible since the public will not trust politicians to keep their promise to stabilize inflation at a low level. As a remedy, Rogoff (1985) suggests institutions that make a low-inflation rule credible, which has usually meant removal of monetary policy-making authority from elected politicians.

The purpose of this paper has been to try to explain central-bank independence as a function of social trust. Interestingly, no previous study of the determinants of central-bank independence has analyzed this relationship, in spite of there being a natural link between the basis for making central banks more independent - i.e., a credibility or lack-of-trust problem - and social trust.

On grounds of theory, social trust can be expected to affect the level of central-bank independence differently depending on the trust level. At high levels of trust we expect a positive effect, since the ability to implement reform is high. Trust entails lower transaction costs of political agreement about reform and makes it easier for politicians to delegate power to independent central bankers. Politicians in high-trusting societies not only trust each other but independent central bankers as well. At low levels of trust, we likewise expect a positive effect, in this case because the perceived need for independence provides a strong incentive to reform the standing of the central bank. This is because the time-inconsistency problem is worse and the credibility of political decisionmaking weaker. Lastly, countries with an intermediate trust level have neither the sufficient perceived need nor the sufficient ability to implement far-reaching reforms, which is why we expect a lower degree of independence for that group. Our empirical results confirm this theoretical reasoning: the relationship between the variables is shown to be $u$-shaped. 
Why is this finding important? We suggest that we contribute to a better understanding of why central-bank independence has been implemented in many countries, by introducing a new variable that has increasingly been shown to matter for economic, political, and social outcomes. Pinpointing the determinants of this type of independence is in turn important since it has been shown to be conducive to lower inflation, a widely shared policy goal.

There is surely more work to be done in this area. Future studies could, e.g., try to address the causality problem in novel ways, possibly through case studies and studies that, through new data, are able to more clearly identify exogenous variation. Lastly, we suggest that social trust is a suitable candidate for future studies on what makes institutional change and reforms in general come about.

\section{Acknowledgements}

We thank Christian Bjørnskov, Cristina Bodea, Joseph Guse and Henrik Jordahl, as well as participants in the 2011 conference of the Midwestern Political Science Association in Chicago, in the 2011 conference of the European Association of Law \& Economics conference in Hamburg, and in the 2012 World Congress of the Public Choice Societies in Miami for valuable comments and suggestions, Christian Bjørnskov for providing data, and Martin Möller for excellent research assistance.

\section{Funding}

The Swedish Research Council (2009-2645 to NB).

\section{References}

Acemoglu, D., Johnson, S., Querubín, P., and Robinson, J.A. (2008) When does policy reform work? The case of central bank independence, Brookings Papers on Economic Activity, 1, 351-418.

Barro, R.J. and Gordon, D.B. (1983) A positive theory of monetary policy in a natural rate model, Journal of Political Economy, 91, 101-21.

Arnone, M., Laurens, B.J., Segalotto, J.-F., and Sommer, B. (2007) Central bank autonomy: lessons from global trends, IMF Working Paper No. 07/88, International Monetary Fund, Washington, DC.

Berger, H., de Haan, J., and Eijffinger, S.C.W. (2001) Central bank independence: an update of theory and evidence, in S. Sayer (ed.) Issues in New Political Economy, Blackwell, Oxford. 
Berggren, N., Elinder, M., and Jordahl, H. (2008) Trust and growth: a shaky relationship, Empirical Economics, 35, 251-74.

Berggren, N. and Jordahl, H. (2006) Free to trust? Economic freedom and social capital, Kyklos, 59, 141-69.

Bergh, A. and Bjørnskov, C. (2011) Historical trust levels predict the current size of the welfare state, Kyklos, 64, 1-19.

Bergh, A. and Erlingsson, G.ó. (2009) Liberalization without retrenchment: understanding the consensus on Swedish welfare state reforms, Scandinavian Political Studies, 32, 7-94.

Bjørnskov, C. (2007) Determinants of generalized trust: a cross-country comparison, Public Choice, 130, 1-21.

Bjørnskov, C. (2010) How does social trust lead to better governance? An attempt to separate electoral and bureaucratic mechanisms, Public Choice, 144, 323-46.

Boix, C. and Posner, D.N. (1998) Social capital: explaining its origins and effects on government performances, British Journal of Political Science, 28, 686-93.

Carmignani, F., Colombo, E., and Tirelli, P. (2008) Economic and socio-political determinants of de facto monetary institutions and inflationary outcomes, The B.E. Journal of Macroeconomics, 8, Article 29.

Cheibub, J., Gandhi, J., and Vreeland, J. (2010) Democracy and dictatorship revisited, Public Choice, 143, 67101.

Crowe, C. and Meade, E.E. (2008) Central bank independence and transparency: evolution and effectiveness. European Journal of Political Economy, 24, 763-77.

Cukierman, A. (1994) Commitment through delegation, political influence and central bank independence, in J.O. de Beauford Wijnholds, S.C.W. Eijffinger, and L.H. Hoogduin (eds) A Framework for Monetary Stability, Financial and Monetary Studies, Kluwer Academic Publishers, Dordrecht.

Cukierman, A. (2008) Central bank independence and monetary policymaking institutions - past, present and future, European Journal of Political Economy, 24, 722-36.

Cukierman, A., Webb, S.B., and Neyapti, B. (1992) Measuring the independence of central banks and its effects on policy outcomes, World Bank Economic Review, 6, 353-98.

Daunfeldt, S.-O. and de Luna, X. (2008) Central bank independence and price stability: evidence from OECD countries, Oxford Economic Papers, 60, 410-22.

Daunfeldt, S.-O., Hellström, J., and Landström, M. (2009) Why do politicians implement central bank independence reforms? Working Paper No. 143, The Ratio Institute, Stockholm.

De Haan, J. and van't Hag, G-J. (1995) Variation in central bank independence across countries: some provisional empirical evidence, Public Choice, 85, 335-51.

Den Butter, F.A.G. and Mosch, R.H.J. (2003) The Dutch miracle: institutions, networks, and trust, Journal of Institutional and Theoretical Economics, 159, 362-91.

Eijffinger, S.C.W. and Hoeberichts, M. (2002) Central bank accountability and transparency: theory and some evidence, International Finance, 5(1), 73-96. 
Ekinci, M.F., Kalemli-Özkan, S., and Sørensen, B.E. (2008) Financial integration within EU countries: the role of institutions, confidence, and trust, in R. Clarida and F. Giavazzi (eds), NBER International Seminar on Macroeconomics 2007, University of Chicago Press, Chicago, IL.

Ferrari, S. and Cribari-Neto, F. (2004) Beta regression for modeling rates and proportions, Journal of Applied Statistics, 31, 799-15.

Forder, J. (1996) On the assessment and implementation of institutional remedies. Oxford Economic Papers, 48, 39-51.

Forder, J. (1998) The case for an independent European central bank: a reassessment of evidence and sources, European Journal of Political Economy, 14, 53-71.

Gilks, W., Richardson, S., and Spiegelhalter, D. (1995) Markov Chain Monte Carlo in Practice, Chapman and Hall, London.

Graham, J.W., Cumsille, P.E., and Elek-Fisk, E. (2003) Methods for handling missing data, in J.A. Schinka and W.F. Velicer (eds) Research Methods in Psychology: Volume 2 of Handbook of Psychology, John Wiley \& Sons, New York, NY.

Grilli, V., Masciandaro, D., and Tabellini, G. (1991) Political and monetary institutions and public financial in the industrial countries, Economic Policy, 13, 341-92.

Guiso, L., Sapienza, P., and Zingales, L. (2008). Trusting the stock market, Journal of Finance, 63, 2557-600.

Guiso, L., Sapienza, P., and Zingales, L. (2009) Cultural biases in economic exchange? Quarterly Journal of Economics, 124, 1095-131.

Hall, P.A. and Thelen, K. (2009) Institutional change in varieties of capitalism, Socio-Economic Review, 7, 7-34 .

Hayo, B. (1998) Inflation culture, central bank independence and price stability, European Journal of Political Economy, 14, 241-63.

Hayo, B. and Hefeker, C. (2002) Reconsidering central bank independence, European Journal of Political Economy, 18, 653-74.

Hayo, B., and Voigt, S. (2008) Inflation, central bank independence, and the legal system, Journal of Institutional and Theoretical Economics, 164, 751-77.

Heinemann, F. and Tanz, B. (2008) The impact of trust on reforms, Journal of Economic Policy Reform, 11, 17385.

Helliwell, J.F. and Wang, S. (2010) Trust and well-being. NBER Working Paper No. 15911, National Bureau of Economic Research, Cambridge, MA.

ILO (2011). LABORSTA database, available at http://laborsta.ilo.org/.

IMF (2011). International financial statistics database, available at http://elibrary-data.imf.org.

Knack, S. and Keefer, P. (1997) Does social capital have an economic pay-off? A cross-country investigation, Quarterly Journal of Economics, 112, 1251-88.

Kydland, F.E. and Prescott, E.C. (1977) Rules rather than discretion: the inconsistency of optimal plans, Journal of Political Economy, 85, 473-90. 
Lundell, K. and Karvonen, L. (2003) A comparative data set on political institutions, Occasional Paper No. 28, Department of Political Science, Åbo Akademi, Åbo.

Mangano, G. (1998) Measuring central bank independence: a tale of subjectivity and of its consequences, Oxford Economic Papers, 50, 468-92.

Marshall, M.G. and Marshall, D.R. (2010) Coup d'état events 1946-2010, available at http://www.systemicpeace.org/inscr/CSPCoupsCodebook2010.pdf

McCallum, B.T. (1997) Crucial issues concerning central bank independence, Journal of Monetary Economics, 39, 99-113.

Maxfield, S. (1997) Gatekeepers of Growth: The International Political Economy of Central Banking in Developing Countries, Princeton University Press, Princeton, NJ.

Morgan Stanley (2004) Morgan Stanley Central Bank Directory 2004. Central Bank Publications, London.

Moser, P. (1999) Checks and balances and the supply of central bank independence, European Economic Review, 43, 1569-93.

Naeff, M. and Schupp, J. (2009) Measuring trust: experiments and surveys in contrast and combination, IZA Discussion Paper No. 4087, Institute for the Study of Labor, Bonn.

Nannestad, P. (2008) New work on trust: what have we learnt, if anything? Annual Review of Political Science, 11, 413-36.

Neumann, M. (1991) Precommitment by central bank independence, Open Economies Review, 2, 95-112.

OECD (2009) Economic Policy Reforms: Going for Growth 2009, OECD, Paris.

Ostrom, E., Cox, J., Walker, J., Castillo, A.J., Coleman, E., Holahan, R., Schoon, M., and Steed, B. (2009) Trust in private and common property experiments, Southern Economic Journal, 75, 957-75.

Posen, A. (1993) Why central bank independence does not cause low inflation: there is no institutional fix for politics, in R. O'Brien (ed.) Finance and the International Economy, Oxford University Press, Oxford.

Rogoff, K. (1985) The optimal degree of commitment to an intermediate monetary target, Quarterly Journal of Economics, 110, 1169-90.

Rose, R. (2000) How much does social capital add to individual health? A survey study of Russians, Social Science and Medicine, 51, 1421-35.

Rubin, D.B. (1987) Multiple Imputation for Nonresponse in Surveys. John Wiley \& Sons, New York, NY.

Sapienza, P., Toldrà, A., and Zingales, L. (2007) Understanding trust. NBER Working Paper No. 13387, National Bureau of Economic Research, Cambridge, MA.

Schafer, J.L. and Graham, J.W. (2002) Missing data: our view of the state of the art, Psychological Methods, 7, 147-77.

Stevenson, B. and Wolfers, J. (2011) Trust in public institutions over the business cycle, NBER Working Paper No. 16891, National Bureau of Economic Research, Cambridge, MA.

Thöni, C., Tyran, J.-R., and Wengström, E. (2009) Microfoundations of social capital, Working Paper No. 09-24, University of Copenhagen, Copenhagen. 
Uslaner, E.M. (2002) The Moral Foundations of Trust, Cambridge University Press, Cambridge.

World Bank (2005) Economic Growth in the 1990s: Learning from a Decade of Reform, World Bank, Washington, DC.

World Bank (2011). World development indicators database, available at http://data.worldbank.org/indicator.

Zak, P.J. and Knack, S. (2001) Trust and growth, Economic Journal, 111, 295-321. 


\section{Tables and figures}

Table 1 Central-bank independence in pre-reform period $\left(\mathrm{CBI}_{89}\right)$ and post-reform period $\left(\mathrm{CBI}_{03}\right)$

\begin{tabular}{lcc}
\hline \hline & $\mathrm{CBI}_{89}$ & $\mathrm{CBI}_{03}$ \\
\hline Mean & 0.350 & 0.586 \\
S.d. & 0.179 & 0.197 \\
Min & 0.090 & 0.190 \\
Max & 0.820 & 1.000 \\
Number of countries & 73 & 149 \\
\hline
\end{tabular}

Table 2 Descriptive statistics and missing observations for explanatory variables

\begin{tabular}{lcccc}
\hline \hline & Mean & S.d. & Missing & Share \\
\hline Pre-reform CBI & 0.25 & 0.12 & 1824 & $51 \%$ \\
Inflation & 0.35 & 0.12 & 428 & $12 \%$ \\
GDP per capita & 0.29 & 0.42 & 336 & $9 \%$ \\
Unemployment & 7992 & 7968 & 1974 & $55 \%$ \\
Federation & 9.22 & 0.32 & 1656 & $46 \%$ \\
IMF credits & 0.44 & 0.49 & 50 & $1 \%$ \\
Party fragmentation & 0.23 & 0.49 & 1494 & $42 \%$ \\
Coups & 5934 & 1444 & 0 & $0 \%$ \\
ESCB membership & 0.19 & 0.43 & 0 & $0 \%$ \\
Democracy & 0.60 & 0.49 & 0 & $0 \%$ \\
Social trust & 0.17 & 0.38 & 1104 & $31 \%$ \\
Number of observations & 149 & & 3576 &
\end{tabular}

Note: Means and standard deviations for explanatory variables correspond to the average value over ten years preceding the implementation of major $\mathrm{CBI}$ reforms in each country. The number of missing observations pertains to the period 1980-2003 for all countries. 
Table 3 Beta regression results aggregated over five imputed samples

\begin{tabular}{lcccc}
\hline $\begin{array}{l}\text { Dependent variable: CBI index } \\
\text { Variable }\end{array}$ & Est & s.d. & ME $^{a}$ & $\%^{b}$ \\
\hline Social trust & $-3.465^{* *}$ & 1.605 & -0.006 & 16.6 \\
Social trust & \\
Pre-reform CBI & $4.667^{* *}$ & 2.301 & 0.011 & 11.7 \\
Inflation & 0.748 & 0.520 & 0.180 & 1.9 \\
GDP per capita & 0.222 & 0.136 & 0.053 & 9.9 \\
Unemployment & -0.008 & 0.095 & -0.002 & 6.8 \\
Federation & 0.005 & 0.162 & 0.001 & 16.9 \\
IMF credits & 0.140 & 0.144 & 0.033 & 30.6 \\
Party fragmentation & -0.053 & 0.093 & -0.013 & 12.6 \\
Coups & $1.569 * * *$ & 0.434 & 0.376 & 7.7 \\
Democracy & -0.027 & 0.098 & -0.007 & 3.7 \\
ESCB membership & $0.235^{*}$ & 0.125 & 0.057 & 7.5 \\
Constant & $1.333^{* * *}$ & 0.193 & 0.275 & 4.9 \\
\hline Log-likelihood & -0.763 & 0.400 & & 3.3 \\
Observations & 87.369 & & & \\
\hline
\end{tabular}

Note: The dependent variable is the central-bank independence index of Arnone et al. (2007). The explanatory variables are the average of the values for the ten-year period preceding CBI reforms (different time periods in different countries).

${ }^{a}$ Marginal effects of each variable while keeping all other variables at their mean values. The marginal effect is the change in the predicted dependent variable for a $1 \%$ change in the explanatory variable, assuming that the effect does not change over that interval.

${ }^{b}$ Percentage of the total variation due to variation in the point estimates between the five samples.

*significant at the $10 \%$ level, $* *$ significant at the $5 \%$ level, ${ }^{* * *}$ significant at the $1 \%$ level. 


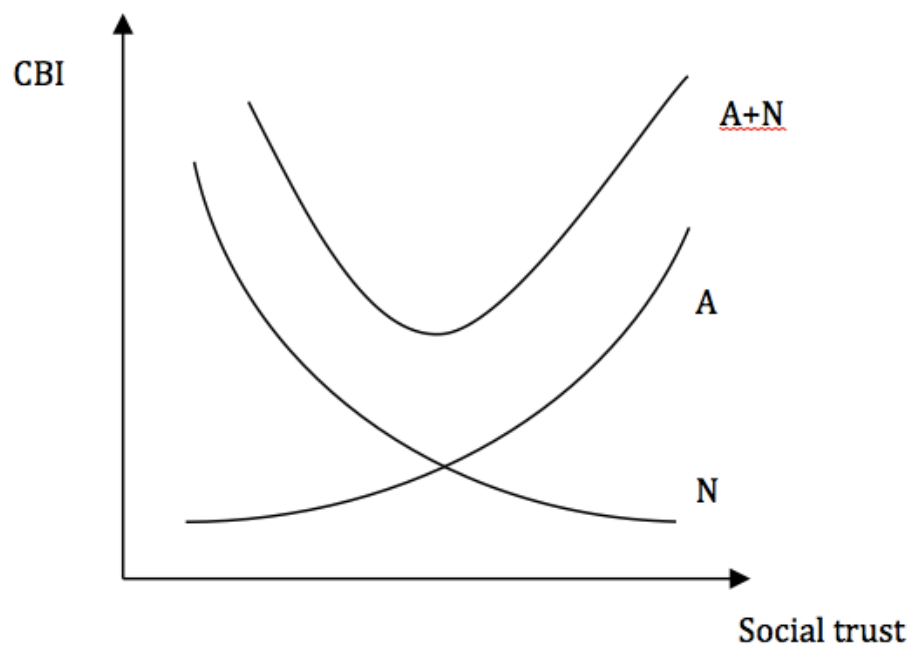

Fig. 1 The relationship between trust and central-bank independence

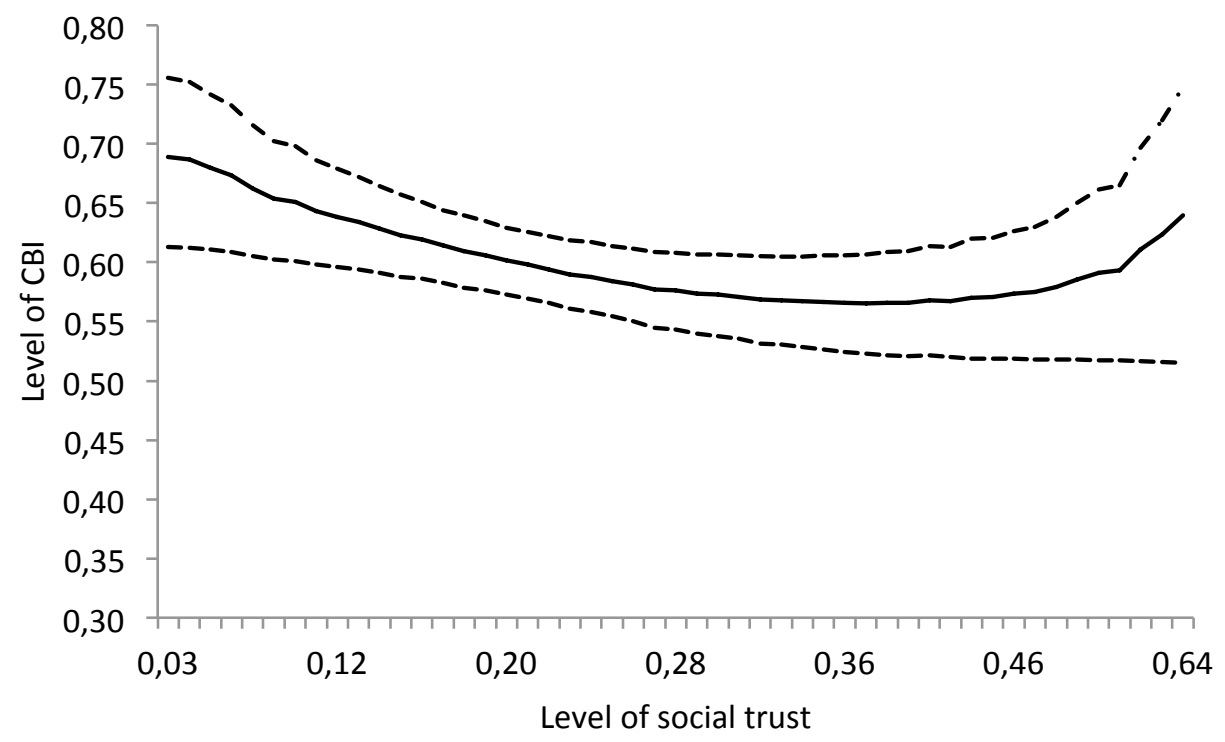

Fig. 2 Fitted equation and 95\% confidence interval for $\mathrm{CBI}$ and social trust 